\title{
USOS DAS FONTES ORAIS: INVENTARIANDO FERRAMENTAS PARA O/A PESQUISADOR/A INICIANTE
}

\author{
SOUZA, N. J.1; FRANTZ, M. L², ALMEIDA, B. D. O. D; SILVEIRA, S. É4
}

PALAVRAS-CHAVE: História Oral. Fontes Orais. Pesquisador/a iniciante.

\begin{abstract}
RESUMO
0 presente artigo tem como objetivo principal apresentar um inventário de ferramentas úteis ao/à pesquisador/a iniciante no que diz respeito à produção, transcrição e análise do material produzido por meio de fontes orais, sem deixar de considerar o caráter mais marcante dessa tipologia de fonte: a subjetividade. Considerada no estabelecimento das dimensões teórico-conceituais da História Oral, a subjetividade se apresenta como um desafio imposto ao/à jovem pesquisador/a que eventualmente se interessar em pesquisar com fontes orais. Procura-se, além de apresentar o inventário de ferramentas relacionado aos usos dessas fontes, refletir sobre o percurso de sua constituição, tendo em vista que a confecção do inventário também se mostrou como uma alternativa frente aos desafios impostos pela investigação científica. A intenção é que as considerações elencadas no artigo possam servir especificamente ao/à pesquisador iniciante em relação às fontes orais e, de maneira mais geral, ao/à jovem pesquisador/a que vive suas primeiras incursões no mundo da pesquisa acadêmica.
\end{abstract}

\section{USES OF ORAL SOURCES: \\ INVENTORYING TOOLS FOR THE BEGINNING RESEARCHER}

KEYWORDS: Oral History. Oral Sources. Beginning researcher.

\begin{abstract}
The main objective of this article is to present an inventory of useful tools to the beginning researcher with regard to the production, transcription and analysis of the material produced thought oral sources, while considering the most striking character of this typology of source: subjectivity. Considered in the establishment of the theoretical and conceptual dimensions of Oral History, subjectivity presents itself as a challenge imposed on the young researcher who may eventually be interested in researching oral sources. In addition to presenting the inventory of tools related to the uses of these sources, it seeks to reflect on the path of its constitution, considering that the preparation of the inventory was also shown as an alternative to the challenges imposed by scientific research.
\end{abstract}

\footnotetext{
${ }^{1}$ Acadêmica do curso de Licenciatura em História na Universidade de Santa Cruz do Sul. Bolsista PIBIC/CNPq. Orcid Id: https://orcid.org/0000-00030172-0176. E-mail: joice15souza@gmail.com.

${ }^{2}$ Acadêmico do Curso de Licenciatura em História na Universidade de Santa Cruz do Sul. Bolsista PUIC/UNISC. Orcid Id: https://orcid.org/0000-00031367-8948. E-mail: leo.muller.frantz@gmail.com.

3 Doutor em História, bolsista de pós-doutorado em Educação (PNPD/Capes) no Programa de Pós-graduação em Educação da Universidade de Santa Cruz do Sul. Orcid Id: https://orcid.org/0000-0001-5715-3591.E-mail: diegoal@unisc.br.

${ }^{4}$ Doutor em História e docente do Programa de Pós-graduação em Educação e do Departamento de Ciências, Humanidades e Educação da Universidade de Santa Cruz do Sul. Orcid Id: https://orcid.org/0000-0002-1242-2126. E-mail: eders@unisc.br.
} 
The intention is that considerations listed in the article may specifically serve the novice researcher in relation to oral sources and, more generally, the young researcher who is experiencing his first forays into the world of academic research.

\section{INTRODUÇÃO}

0 artigo que segue tem o objetivo de apresentar um inventário de ferramentas que podem ser utilizadas pelo/a pesquisador/a iniciante para a produção, transcrição e análise de fontes orais. Além de apresentar o inventário, resultado da pesquisa, optou-se por discorrer, também, sobre o percurso de sua construção, entendendo-o como um dos desafios que se impôs aos/às pesquisadores/as iniciantes e seus papéis como bolsistas de Iniciação Científica. Percurso e resultados são apresentados de modo a servir como um meio de interlocução com outros/as pesquisadores/as e acadêmicos/as iniciantes que se aventuram pelo mundo da investigação científica. 0 inventário de ferramentas para o trabalho com fontes orais serve especificamente ao/à pesquisador/a que se dedica à utilização de entrevistas como fonte de pesquisa. Ele foi constituído por meio das metodologias associadas à abordagem da História Oral e aos instrumentos de trabalho em relação aos usos da oralidade. Acreditamos que as reflexões sobre o percurso de constituição desse inventário poderão servir para um público um pouco mais amplo, já que o inventário se configurou como uma alternativa frente a um desafio imposto em nosso grupo de pesquisa durante o percurso de nossa inserção investigativa. Ao mesmo tempo, não temos a pretensão de constituir qualquer "manual infame" (CORAZZA, 2012), embora haja o desejo de compartilhar uma sistematização útil à nossa instrumentalização para o trabalho com entrevistas.

A iniciativa e a construção do inventário de ferramentas em relação às fontes orais são parte do percurso de investigação associado ao projeto Narrativas sobre políticas e experiências de Ensino Médio em Tempo Integral na América Latina, que vem sendo desenvolvido junto ao Grupo de Pesquisa Currículo, Memórias e Narrativas em Educação - CNPq, vinculado ao Programa de Pós-graduação em Educação da Universidade de Santa Cruz do Sul (PPGEdu/UNISC). Esse projeto, de cunho qualitativo, situa-se na intersecção entre os eixos História da Educação e Políticas Educacionais Curriculares e visa compreender e problematizar histórias, narrativas e experiências referentes às políticas em torno do Ensino Médio de Tempo Integral no contexto das reformas educacionais na América Latina. A utilização de ferramentas para fontes orais guarda relação com a terceira etapa dessa investigação, de caráter empírico, cuja produção de dados associa-se à realização de entrevistas pelos membros do grupo nas escolas envolvidas na pesquisa. A previsão de realização de entrevistas com alunos/as, educadores/as e representantes da direção e/ou coordenação das escolas, do Brasil e fora do país, trouxe algumas discussões para o Grupo de Pesquisa sobre como, afinal, se dariam essas entrevistas. Deveria haver um questionário estruturado? Quais deveriam ser os cuidados éticos comuns às pesquisas qualitativas que se utilizam das fontes orais em seu percurso metodológico? Como, afinal, elaborar a entrevista? Ao longo dos encontros do Grupo de Pesquisa, foi se constituindo uma espécie de "acervo virtual" com autores/as referências no trabalho com fontes orais e com a abordagem da História Oral. Esse "acervo", uma vez constituído, passou a ser analisado, primeiramente, através de leituras realizadas em grupo e, depois, por divisão de tarefas individuais.

A constituição do inventário foi uma ideia que surgiu gradualmente, aparecendo nas discussões realizadas pelo Grupo de Pesquisa a partir das leituras individuais e coletivas dos textos escolhidos. 
Primeiramente foi realizada uma leitura de caráter exploratório, por meio da qual buscou-se conhecer autores/as, ideias e suas proposições. Essa leitura, que caracterizou a fase inicial de aproximação com textos e conceitos específicos, tanto relacionados às ferramentas de fontes orais quanto às dimensões teórico-conceituais da História Oral, possibilitou que se impusessem indagações quanto à organização desse conjunto de informações. 0 que, especificamente, os/as autores/as consideram imprescindível no que diz respeito ao trabalho com as fontes orais? Para organizar todas essas premissas, ao invés de pensá-las apenas isoladamente, optou-se por colocar todas as propostas dos/as autores/as em uma perspectiva ampliada, em interlocução. Assim, a constituição de um inventário mostrou-se uma opção interessante diante do desafio de organização de um número extenso de recomendações e prescrições acerca dos modos de utilização de fontes orais.

0 texto divide-se em dois segmentos: no primeiro, de ordem teórico-metodológica, busca-se, considerando a posição de pesquisadores/as iniciantes, apontar algumas reflexões acerca do percurso de constituição do inventário de ferramentas para os usos das fontes orais; no segundo, expõe-se a discussão dos resultados da pesquisa, ou seja, o próprio inventário e seu conteúdo. Considera-se que, além de apresentar os resultados da pesquisa, refletir sobre o percurso e seus desafios contribui não só com pesquisadores/as iniciantes especificamente interessados/as nas fontes orais ou na História Oral, mas com um público mais amplo de jovens pesquisadores/as que se defrontam com os primeiros desafios da pesquisa acadêmica/científica. Já que o artigo trata do percurso de investigação de jovens pesquisadores/as, apresentar os resultados sem considerar seu processo de constituição não faria sentido.

\section{AFINAL, POR QUE UM INVENTÁRIO? O PERCURSO DE INVESTIGAÇÃO E OS DESAFIOS DO/A PESQUISADOR/A INICIANTE NO USO DAS FONTES ORAIS}

Por que construir um inventário? A pergunta mobiliza uma reflexão acerca dos desafios do/a pesquisador/a iniciante em relação aos usos das fontes orais - mas também no que diz respeito aos desafios impostos pela pesquisa acadêmica de modo geral. Constituir um inventário de ferramentas para os usos das fontes orais poderá, é claro, servir ao/à pesquisador iniciante que eventualmente se interessar por esse campo de estudos vinculado à abordagem da História Oral. A reflexão sobre o percurso de constituição do inventário de ferramentas impõe outra questão que, de certa forma, se configura como um desafio de todo/a pesquisador/a iniciante: a criação de alternativas frente aos desafios impostos durante o percurso da pesquisa. Para demonstrar como se deu a iniciativa e a constituição do inventário de ferramentas, deve-se levar em consideração, em primeiro lugar, uma indagação fundamental e que se configura como uma dúvida de boa parte dos/as pesquisadores/as iniciantes: o que é, afinal, importante reter na leitura de um texto acadêmico que será utilizado em uma pesquisa? 0 desafio específico foi, no caso, o de apreender as considerações mais significativas dos/as autores/as acerca dos usos das fontes orais e das metodologias associadas à História Oral. Assim, a opção de constituir um inventário surgiu como um modo de tornar inteligível no Grupo de Pesquisa quais seriam as principais ferramentas e os cuidados metodológicos em relação às possibilidades e usos de fontes orais, e também uma maneira de apresentá-las de uma forma mais simples, ainda que não de modo simplista. Identificou-se, portanto, a necessidade de se ter um conjunto de premissas ou pressupostos que pudessem balizar o desenvolvimento e a realização da terceira etapa, vinculada ao campo empírico de nosso projeto de pesquisa. 
Isto é, a constituição do inventário surgiu de um desafio imposto por uma investigação maior desenvolvida no Grupo de Pesquisa, um enfrentamento do próprio percurso. Dúvidas sobre quais seriam os pressupostos defendidos pelos/as diferentes autores/as e os que poderiam ser considerados mais significativos apareceram ao longo das nossas discussões. Antes de simplesmente optar por um/a autor/a ou uma só perspectiva, preferiuse enfrentar a multiplicidade de abordagens, buscando o que era comum entre as diferentes proposições, mas também aquilo que era específico, ainda que complementar no que diz respeito às metodologias empregadas.

Ao se defrontar com o campo de estudos específico e as metodologias relacionadas aos usos das fontes orais, primeiramente, realizou-se a leitura exploratória de caráter geral sobre as dimensões teórico-conceituais da História Oral e, posteriormente, sobre as possibilidades e os usos das fontes orais. Na verdade, para ser possível se trabalhar com as fontes orais, era preciso, antes, conhecer as diretrizes conceituais e teóricas da História Oral, percebendo sua inserção no campo historiográfico. A par das considerações, surgidas da leitura exploratória, partiu-se para a análise das proposições dos/as diversos/as autores/as acerca dos pressupostos/premissas para os usos das fontes orais na pesquisa acadêmica.

Constata-se, atualmente, uma profusão de produções acadêmicas que têm buscado refletir acerca das dimensões teórico-conceituais da História Oral e sobre os múltiplos usos das fontes orais. Além disso, uma série de autores/as têm se dedicado a pensar, afinal, as dimensões teórico-conceituais da História Oral inserida em um campo de estudos. Ressalta-se, dentre as principais considerações, as possibilidades de alargamento do campo de ação da História, o aprofundamento das experiências individuais e de grupo, as múltiplas visões sobre determinados temas tradicionalmente já trabalhados por outros ramos da historiografia. Trata-se, no entanto, de uma abordagem não apenas ligada aos/às historiadores/as, mas, também, às pesquisas qualitativas de forma geral. Essa abordagem permite que se encontre "heróis vindos não só dentre os líderes, mas dentre a maioria desconhecida do povo" (PORTELLI, 1992, p. 44), isto é, permite a emergência e participação de homens e mulheres, independentemente de classe e hierarquia social, na pesquisa científica. Segundo Verena Alberti (2018, p. 165), a História Oral também pode possibilitar o estudo dos modos pelos quais "pessoas ou grupos efetuaram e elaboraram experiências, incluindo situações de aprendizado e decisões estratégicas". Ainda que a História Oral diga respeito a "padrões culturais, estruturas sociais e processos históricos", seu objetivo é o de "aprofundá-los, em essência, por meio de conversa com pessoas sobre a experiência e a memória individuais" (PORTELLI, 1997, p. 13). Em síntese, a História Oral pode ser compreendida como uma história que é:

[...] construída em torno de pessoas. Ela lança a vida para dentro da própria história e
isso alarga seu campo de ação. Admite heróis vindos não só dentre os líderes, mas
dentre a maioria desconhecida do povo. Estimula professores e alunos a se tornarem
companheiros de trabalho. Traz a história para dentro da comunidade e extrai a história
de dentro da comunidade. Ajuda os menos privilegiados, e especialmente os idosos, a
conquistar dignidade e autoconfiança. Propicia o contato - e, pois, a compreensão -
entre classes sociais e entre gerações. (THOMPSON, 1992, p. 44).

Além das considerações acerca das dimensões teórico-conceituais, os/as pesquisadores/as refletiram também acerca do papel das fontes orais. As fontes orais são de especial interesse aos/às historiadores/as que se interessam pelo universo dos múltiplos significados, representações, crenças, valores e atitudes que permitem uma compreensão das diferentes experiências do mundo social. Para Alessandro Portelli (1997, p. 31), as fontes orais teriam um "único e preciso elemento" e que "nenhuma outra fonte possui em medida igual", trata-se da "subjetividade do expositor", que pode fazer emergir diferentes subjetividades "de grupo ou classe". Ou seja, as 
"fontes orais contam-nos não apenas o que o povo fez, mas o que queria fazer, o que acreditava estar fazendo e o que agora pensa que fez" (PORTELLI, 1997, p. 31). A fonte oral, assim como as outras fontes, é para Paul Thompson (1992, p. 197) "derivada da percepção humana" que é subjetiva, ainda que "apenas a fonte oral permite-nos desafiar a subjetividade: descolar as camadas da memória, cavar fundo em suas sombras, na expectativa de atingir a verdade oculta" (sic).

Tanto as concepções que entendem a História Oral como uma possibilidade de aprofundar temas e objetos de estudo tradicionalmente estudados pela historiografia, quanto as considerações acerca da subjetividade enquanto característica da fonte oral se complementam na afirmação de um campo de estudos que vem se consolidando nas últimas décadas. A atual profusão de proposições e considerações, que diz respeito aos usos das fontes orais, portanto, exigiu a realização de uma análise mais detalhada.

Para além de apenas uma revisão bibliográfica (BARROS, 2015) ou de se fazer tão somente um fichamento (DINIZ; SILVA, 2008), a opção pelo inventário se deu, como já colocado, para visualizar mais detidamente quais seriam as principais proposições dos/as diversos/as autores/as sobre os usos das fontes orais, os cuidados que devem ser tomados, as premissas e os pressupostos que, afinal, balizam sua utilização. Para a análise das proposições dos/as autores/as utilizamos as considerações de Maria Cecília de Souza Minayo (2012, p. 622), que aponta para a importância do reconhecimento, por meio da leitura metódica, dos termos principais que estruturam os textos analisados e que, ao mesmo tempo, são considerados fundamentais para o/a pesquisador/a. Os termos estruturantes encontrados nas proposições dos/as autores/ evocam três momentos que dimensionam os usos das fontes orais: produção, transcrição e análise. As referências utilizadas na constituição do inventário de ferramentas foram: de Verena Alberti, Histórias dentro da História publicado pela Contexto em 2008; de autoria de Alessandro Portelli, 0 que faz a história oral diferente e História Oral como Gênero ambos publicados em Projeto História, respectivamente em 1997 e 2001; Antoinette Errante, Mas afinal, a memória é de quem? Histórias Orais e Modos de Lembrar e Contar publicado na História da Educação/ASPHE, em 2000. A elaboração de um quadro-síntese reuniu as premissas e os apontamentos encontrados nos textos acerca do trabalho com as fontes orais. As temáticas principais associadas foram: memória social e coletiva, narrativa (auto)biográfica e entrevistas/narrativas qualitativas. Elas foram cruzadas com três eixos metodológicos: produção, transcrição e análise de narrativas orais. Assim, as premissas e apontamentos foram analisados como indicadores relevantes e significativos para a elaboração de um inventário de ferramentas para a utilização das fontes orais.

\section{Quadro 1: Categorias e Premissas nos usos das fontes orais}

\begin{tabular}{|c|c|c|c|}
\hline CATEGORIAS & $\begin{array}{c}\text { PRODUÇÃO } \\
\text { planejamento e } \\
\text { realização da entrevista }\end{array}$ & $\begin{array}{c}\text { TRANSCRIÇÃO } \\
\text { metodologias para } \\
\text { transcrição da entrevista }\end{array}$ & $\begin{array}{c}\text { ANÁLISE } \\
\text { cautela e análise crítica } \\
\text { do documento }\end{array}$ \\
\hline $\begin{array}{c}\text { Premissas encontradas } \\
\text { nos artigos/capítulos } \\
\text { sobre Entrevista } \\
\text { qualitativa/narrativa }\end{array}$ & $\begin{array}{c}\text { Espaço da Entrevista; } \\
\text { Relação interpessoal; } \\
\text { Justificativa de Pesquisa; } \\
\text { Gatilhos (dispositivos) de } \\
\text { memória; } \\
\text { Relatos de Ação. }\end{array}$ & $\begin{array}{c}\text { Sumários e Índices } \\
\text { temáticos; } \\
\text { Ocultação Verbal; } \\
\text { Emoções; } \\
\text { Perspectiva; } \\
\text { Grupo Social; } \\
\text { Variações Temporais. }\end{array}$ & $\begin{array}{c}\text { Crítica; } \\
\text { Contexto; } \\
\text { Perspectiva; } \\
\text { Distância; } \\
\text { Intenção; } \\
\text { Resíduos de Ação. }\end{array}$ \\
\hline
\end{tabular}




\begin{tabular}{|c|c|c|c|}
\hline $\begin{array}{c}\text { Premissas encontradas } \\
\text { nos artigos/capítulos } \\
\text { sobre memória sociale } \\
\text { coletiva }\end{array}$ & $\begin{array}{c}\text { Justificativa de Pesquisa; } \\
\text { Esfera Pública; } \\
\text { Grupo Social; } \\
\text { Relatos de Ação. }\end{array}$ & $\begin{array}{c}\text { Contexto; } \\
\text { Variações Temporais; } \\
\text { Espaço da Entrevista; } \\
\text { Esfera Pública; } \\
\text { Esfera Privada; } \\
\text { Grupo Social. }\end{array}$ & $\begin{array}{c}\text { Crítica; } \\
\text { Contexto; } \\
\text { Esquecimento; } \\
\text { Silêncio; } \\
\text { Discurso Coletivo; } \\
\text { Esfera Pública; } \\
\text { Esfera privada; } \\
\text { Grupo Social. }\end{array}$ \\
\hline $\begin{array}{c}\text { Premissas encontradas } \\
\text { nos artigos/capítulos } \\
\text { sobre narrativa } \\
\text { (auto)biográfica }\end{array}$ & $\begin{array}{c}\text { Sujeitos de Pesquisa; } \\
\text { Gatilhos (dispositivos) de } \\
\text { memória; } \\
\text { Experiência; } \\
\text { Relatos de Ação; } \\
\text { Esfera Privada; } \\
\text { Esfera Pública. }\end{array}$ & $\begin{array}{c}\text { Subtexto; } \\
\text { Variações Temporais; } \\
\text { Perspectiva; } \\
\text { Esfera Pública; } \\
\text { Esfera Privada; } \\
\text { Ocultação Verbal. }\end{array}$ & $\begin{array}{c}\text { Crítica; } \\
\text { Perspectiva; } \\
\text { Distância; } \\
\text { Intenção; } \\
\text { Organização da } \\
\text { experiência; } \\
\text { Resíduos de Ação. }\end{array}$ \\
\hline
\end{tabular}

Fonte: elaboração dos autores, 2019.

0 cruzamento, de caráter metodológico, de categorias e premissas, permitiu organizar as proposições dos/as diversos/as autores/as de modo a subsidiar a visualização sintetizada de todo o percurso da pesquisa realizada que orientou a constituição do inventário de ferramentas acerca dos possíveis usos de fontes orais. Cada uma das categorias pode ser subdividida a partir das premissas consideradas. Produção, transcrição e análise, caracterizam-se como passos operacionais importantes no trabalho com fontes orais e se desdobram em outras três premissas consideradas pelos diversos/as autores/as: entrevista qualitativa/narrativa, memória social e coletiva e narrativa (auto)biográfica. A produção se refere ao planejamento e realização da entrevista, não é só a preparação e tudo aquilo que a antecede, mas sua construção contínua, inclusa no processo de realização. A transcrição guarda relação com as metodologias e os meios mais adequados para se transcrever entrevistas de forma que auxilie a próxima etapa do trabalho. A análise, por fim, está associada aos cuidados de organização e interpretação crítica daquilo que é suscitado nas fontes orais. Todas essas premissas e categorias, relacionadas às etapas operacionais que envolvem o necessário trabalho com as fontes orais, refletem, nos/as pesquisadores/as analisados/as, a preocupação com a questão da subjetividade, característica mais marcante das fontes orais. Adequadamente encadeadas, todas essas referências permitem que se produza um trabalho de pesquisa a partir dos usos das fontes orais e suas múltiplas possibilidades. Resta explicar cada uma dessas importantes referências e apresentar o inventário de ferramentas para os usos das fontes orais.

\section{PRODUÇÃO, TRANSCRIÇÃOE ANÁLISE: O INVENTÁRIO DE FERRAMENTAS PARA OS USOS DE FONTES ORAIS}

Os indicadores em torno da produção relacionam-se às concepções metodológicas referentes ao planejamento, preparação e a tudo aquilo que antecede e, ao mesmo tempo, faz parte da realização das entrevistas. Portanto as premissas reunidas são relativas, principalmente, aos cuidados de escolha dos sujeitos 
de pesquisa, à definição dos objetivos principais da entrevista e às formas de estimular os entrevistados a colaborarem com esses objetivos, aos gatilhos de memória. Verena Alberti (2018, p. 172) diz que a preparação das entrevistas deve incluir o próprio projeto de pesquisa além da elaboração dos roteiros da entrevista. No projeto de pesquisa, de acordo com a pesquisadora, deve-se:

\begin{abstract}
[...] discutir e tentar definir que tipo de pessoa será entrevistada, quantos serão entrevistados e qual o tipo de entrevista será realizado. Essas escolhas serão condicionadas pelos objetivos da pesquisa: "quem entrevistar?" Depende de "o que quero saber?". A decisão deve basear se em critérios qualitativos, como a posição dos entrevistados no grupo e o significado de sua experiência (ALBERTI, 2018, p. 172).
\end{abstract}

No planejamento das entrevistas, alguns cuidados metodológicos são recomendados pelos/as autores/as analisados. Algumas perguntas básicas, imprescindíveis: Por quê? - Questão que deve ser relacionada à justificativa presente no projeto de pesquisa; Quem? - Pergunta que guarda relação com a delimitação de quais serão, afinal, os sujeitos da pesquisa, os/as entrevistados/as; Como? - Indagação acerca da elaboração dos roteiros de entrevista; Onde e quando? - Pergunta sobre o(s) ambiente(s) em que as entrevistas serão realizadas.

Primeiramente, as entrevistas devem possuir uma justificativa que incorpore sua importância ao projeto de pesquisa. Uma justifica que guie o planejamento, a definição dos sujeitos da pesquisa, o que abarca definir os grupos sociais que serão objetos da investigação. A seleção dos indivíduos escolhidos deve ser acompanhada de breves pesquisas bibliográficas para definição de perfis individuais com dados pessoais e profissionais, e, se possível, traçar motivações pessoais e políticas dos selecionados. Esse planejamento incorre na elaboração dos roteiros de entrevistas. Sobre isso, especificamente, Verena Alberti (2018, p. 176) propõe a criação de um roteiro geral e de roteiros individuais: o roteiro geral guarda "dupla função" pois sistematiza "os dados levantados durante a pesquisa exaustiva sobre o tema", permitindo "a articulação desses dados com as questões que impulsionam o projeto, orientando, dessa forma, atividades subsequentes". Vale destacar que, na fase de escolha e do planejamento, é importante fazer uma primeira aproximação com os sujeitos, buscando estabelecer pontes e vínculos que Ihes permitam desejar participar do processo. Especialmente em pesquisas qualitativas, uma aproximação com os sujeitos pode contribuir para que estes sintam-se colaboradores e/ou participantes e não apenas "objeto" ou "fonte" da pesquisa. Este procedimento é relevante uma vez que de nada vale a "escolha" ocorrer de forma unilateral e os sujeitos não desejarem conceder a entrevista.

0 roteiro geral é estruturado a partir de uma série de questionamentos e informações, como cronologias, documentos, leis, entre outros, que auxiliem o/a pesquisador/a a adquirir os conhecimentos necessários sobre os/as entrevistados/as. Trata-se da base dos roteiros individuais, que constituem o cruzamento do roteiro geral com as especificidades dos perfis individuais constituídos. Nos roteiros individuais deverão aparecer adicionadas as informações específicas do perfil do/a entrevistado/a, bem como questionamentos específicos para obtenção de informações que apenas determinados indivíduos têm acesso. É importante lembrar, ainda, de se deixar um espaço para anotações próprias, como comentários e questões que surgem durante e após o diálogo. Este deve ser constituído de forma orgânica. 0 roteiro é importante para a construção da entrevista, mas uma entrevista "fria", direcionada exclusivamente por um único roteiro, poderá resultar em perdas de importantes informações para a pesquisa. Com isso, é imprescindível o domínio da temática pelo/a entrevistador/a, uma vez que o diálogo flui melhor através da mútua troca de informações sobre o tema. De acordo com Alberti (2018, p. 177), “essa 
preparação dá ao entrevistador segurança no momento de realização da entrevista, pois ele saberá bem o que e como perguntar", além disso, “poderá reconhecer respostas insatisfatórias e identificar 'ganchos' relevantes para a formulação de novas perguntas".

Mesmo que se advogue em favor da premissa de que o/a entrevistador/a deve possuir experiência prévia com o tema escolhido, Antoinette Errante (2000) destaca que a falta de experiência a respeito do tema estudado pode ter efeitos positivos. 0 mais importante é que os/as entrevistados/as se disponham a explicar, em detalhes, as informações necessárias, fornecendo-Ihe dados mais proeminentes da pesquisa. Porém, tal abordagem não é recomendada, principalmente porque requer predisposição do/a entrevistado/a no que toca ao esclarecimento de conteúdos de embasamento teórico. A falta desse domínio pelo/a entrevistador/a pode desperdiçar tempo da entrevista, que poderia ser reservado a perguntas mais pertinentes.

No roteiro da entrevista podem constar, ainda, questionamentos e afirmações que poderão servir ao/à entrevistador/a para estimular rememorações do/a entrevistado/a sobre um determinado assunto: são os gatilhos ou dispositivos de memória. 0 gatilho dispara uma reação quando acionado, e é essa sua função na entrevista. 0 gatilho é um estímulo aos sentidos do entrevistado que cumpre o papel de incitar suas memórias. “Ao perguntar, por exemplo, 'como era a relação professor alunos?', os narradores frequentemente relembravam o cheiro e a disposição da escola, as práticas disciplinares, os modelos de ensino para instrução, as atitudes para com a cultura local, [...]" (ERRANTE, 2000, p. 149).

Não é preciso, necessariamente, limitar-se às perguntas. Pode-se considerar o ambiente. Como exemplo, uma pesquisa/investigação sobre "metodologia de ensino" poderá, provavelmente, extrair mais informações do/a professor/a se a entrevista for realizada em uma sala de aula. Por se tratar de um tema associado ao "ensino", a sala de aula, na escola, propiciará estímulos sensoriais que poderão trazer à tona ainda mais memórias a serem compartilhadas. Portanto, o local da entrevista terá impacto sobre as respostas, uma vez que elas irão se adequar aos estímulos e à formalidade proporcionada pelo espaço onde a entrevista for realizada.

Por fim, o planejamento deve incluir algumas ferramentas para a realização da entrevista. A clareza do áudio é, neste caso, essencial e poderá ser assegurada por gravadores e microfones de boa qualidade. Se autorizado pelo/a entrevistado/a, a utilização de uma câmera com excelente qualidade de imagem, será importante para análise da linguagem corporal. Lembrando que é essencial comunicar aos/às entrevistados/as sobre o termo de consentimento a ser assinado logo após a entrevista. Este deve ser elaborado para abranger a todos os pontos da cessão de direitos sobre os conhecimentos, imagens e áudios produzidos pela entrevista.

Outro aspecto a ser destacado é que os/as entrevistados/as apresentam, em geral, sua face pública, ou seja, sua imagem na esfera pública. Isso acontece quando se trata de uma entrevista compreendida como oficial, principalmente em ambientes caracterizados por traços de formalidade. Alessandro Portelli $(1997$, p. 30) ressalta esse aspecto ao analisar os padrões e os descompassos da linguagem em sua aproximação entre o discurso individual e o coletivo:

Uma estrutura recorrente típica é aquela na qual a linguagem standard é usada de um extremo ao outro, enquanto o dialeto brota em digressões e anedotas singelas, coincidindo com um envolvimento mais pessoal do narrador ou (como quando as ocorrências de dialeto coincidem com linguagem formalizada) a intrusão da memória coletiva. De outro lado, a linguagem padrão pode emergir em um dialeto narrativo quando se relaciona com temas mais profundamente conectados com a esfera pública, tal como a política (PORTELLI, 1997, p. 30). 
Isso significa que os entrevistados/as poderão reproduzir, muitas vezes inconscientemente, ideias da memória coletiva, uma vez que se encontram em um ambiente público e veem como uma responsabilidade para com seu grupo social representar seus ideais e mitigar eventuais conflitos e problemas que o grupo ao qual pertence enfrenta. Uma das formas de amenizar é possuir boas relações interpessoais com os entrevistados e estabelecer uma relação de troca de informações. Esse procedimento pode contribuir para que o/a entrevistador/a transmita segurança, fazendo com que os/as entrevistados/as se sintam mais à vontade em compartilhar experiências próprias, que podem ir tanto ao encontro como de encontro à memória coletiva, da qual os sujeitos também são porta-vozes.

Outro conceito importante presente no trabalho de Verena Alberti (2008) é a noção de resíduos e relatos de ação, desenvolvido pelo historiador alemão Peter Hüttenberg. De acordo com ela, essa noção sugere dividir os vestígios do passado em resíduos de ação. A ideia de resíduo, um "pedaço de uma ação passada" (ALBERTI, 2008, p. 168), como um documento de um arquivo, difere de da ideia de relatos de ação, que são posteriores aos resíduos, podendo ser constituídos em cartas, memórias e autobiografias. Entretanto ela destaca que todo relato é também um resíduo de ação que seu/sua autor/a desencadeia ao criá-lo: a entrevista de História Oral é resíduo de uma ação específica, qual seja, a de interpretar o passado. "A entrevista deve ser tomada como "resíduo de ação, e não apenas como relato de ações passadas". É preciso chamar atenção que a entrevista pode "documentar as ações de constituição de memória" (ALBERTI, 2008, p. 169).

O/A entrevistador/a deve permanecer muito atento/a aos comportamentos e ao discurso do entrevistado. Gestos, expressões e emoções devem ser anotados. A filmagem, se houver, é muito importante para este item, uma vez que as imagens podem revelar pontos de vista importantes para a posterior análise e são indicativos da aparição de comportamentos relacionados à ocultação verbal. Antoinette Errante (2000, p. 159) destaca os seguintes comportamentos:

\footnotetext{
Mitigação: uma palavra ou frase que tenta minimizar a importância ou a dor de uma experiência;

Abstração: quando o narrador começa a falar de um evento de maneira enviesada, usando linguagem passiva para deslocar o agente, ou referindo-se a "eles" mais do que se referindo a alguém diretamente;

Negação - do sentimento ou da experiência. (Isso é normalmente acompanhado por explicações prolongadas de seus sentimentos);

Defensiva: ou irritação, usualmente resultando sentimentos de vulnerabilidade ao ser "desmascarado" pelo entrevistador. (Isso pode ser acompanhado de pequenas frases, em rápida sucessão);

Distração: o narrador muda a discussão a partir de uma questão ou experiência que evoca emoção;

Fugas Verbais: assinaladas por mudanças nos padrões de expressão verbal incluindo respostas curtas e longas pausas [...]. Experiências dolorosas também podem estar escondidas por trás de generosas pistas paralingüísticas inconscientes (Retzinger, 1991). 0 mais comum nas histórias orais moçambicanas era baixar o volume [da voz] (ERRANTE, 2000, p. 159).
}

Por isso é importante levar em consideração os possíveis objetivos do entrevistado com a entrevista, uma vez que interesses individuais, ou coletivos de seu grupo social, podem interferir em seu relato, conscientemente ou não. Complementando esse conceito, Alessandro Portelli (1997) alerta os pesquisadores quanto às mudanças forjadas pela memória, que buscam um sentido no passado para dar forma às suas vidas, colocando a narração em seu contexto histórico, “[...] o importante é não ser a memória apenas um depósito passivo de fatos, mas também um processo ativo de criação de significações" (PORTELLI, 1997, p. 33). 
Ainda que os roteiros sejam importantes, além dos conceitos-chave para o momento de realização da entrevista, em muitas ocasiões, os comportamentos do/a entrevistado/a não podem passar despercebidos por parte do/a entrevistador/a. Daí a significativa importância de se levar um bloco de notas ou de reservar um espaço de observações no roteiro para anotações pertinentes ao comportamento do/a entrevistado/a.

Na transcrição, os indicadores auxiliam na identificação de cuidados metodológicos para o processo de reprodução textual do material audiovisual produzido pela entrevista. Como exemplo, os comportamentos de ocultação verbal e as reações emocionais do entrevistado, assim como outras observações pertinentes, devem ser inseridas em uma coluna própria, junto da passagem da qual é pertinente. A seguir, um exemplo, do diário de campo de Antoinette Errante (2000, p. 161), sobre como a inclusão de uma coluna com as reações emotivas pode complementar qualitativamente um diálogo de entrevista.

\section{Quadro 2 - Exemplo de organização da transcrição com ínclusão de anotações de diárío de campo}

\begin{tabular}{|c|c|c|}
\hline $\begin{array}{c}\text { DIÁLOGO } \\
\text { A=Antoinette } \quad N=\text { Narrador }\end{array}$ & REAÇÕES EMOTIVAS & $\begin{array}{l}\text { COMPORTAMENTO } \\
\text { DE OCULTAÇÃOO }\end{array}$ \\
\hline $\begin{array}{l}\text { (Sem nenhuma pressão minha, o narrador gasta os } 15 \\
\text { minutos prévios descrevendo o papel importante que } \\
\text { os professores "indígenas" exerceram preparando } \\
\text { pessoas para a independência) } \\
\text { A: O que você fez depois da independência? } \\
\text { N:Depois da independência, bem, eu continuei } \\
\text { lecionando por um período, depois eu desisti. } \\
\text { A: Você poderia me contar sobre suas experiências de } \\
\text { ensino depois da independência? }\end{array}$ & $\begin{array}{l}\text { Ele parecia especialmente } \\
\text { orgulhoso do papel que os } \\
\text { professores "indígenas" } \\
\text { exerciam e discutia isso longa e } \\
\text { animadamente. } \\
\text { Seu arnimoridou } \\
\text { consideravelmente assim que } \\
\text { nós chegamos ao período pós- } \\
\text { independência... }\end{array}$ & Fuga verbal \\
\hline $\begin{array}{l}\text { N: Humpf... O que contar? Eu continuei a exercer meu } \\
\text { trabalho, é tudo. Então me fartei. Eu não quis mais } \\
\text { lecionar. }\end{array}$ & $\begin{array}{l}\text { Formal e polido até aqui, parece } \\
\text { irritado pelas perguntas de pós- } \\
\text { independência. }\end{array}$ & $\begin{array}{l}\text { Irritação } \\
\text { Negação }\end{array}$ \\
\hline \multicolumn{3}{|l|}{ A: Você se cansou de lecionar? } \\
\hline N: Humpf... Eles cansaram de mim Nós éramos & $\begin{array}{l}\text { Passou a evitar contato visual e } \\
\text { esfregar as mãos. }\end{array}$ & Irritação \\
\hline $\begin{array}{l}\text { [volume mais baixo] colaboradores coloniais. Nós } \\
\text { tínhamos feito parte do sistema, então, agora, tudo } \\
\text { que nós fazíamos era suspeito. }\end{array}$ & Ficou aflito, apertou os lábios. & Abstração \\
\hline $\begin{array}{l}\text { Eh... Eu mesmo fiquei cansado de vê-los queimando } \\
\text { tudo, [volume mais baixo] todos aqueles livros bonitos. }\end{array}$ & $\begin{array}{l}\text { Gesticulava para tirar a } \\
\text { importância, mas baixa a } \\
\text { cabeça e fica alguns segundos } \\
\text { pensativo. }\end{array}$ & Mitigação \\
\hline \multicolumn{3}{|l|}{ A: Quem estava queimando os livros? Por quê? } \\
\hline $\begin{array}{l}\text { N: Quem estava queimando os livros, eram os } \\
\text { soldados, eram eles. Livros, equipamentos científicos. } \\
\text { Se fosse português tinha que ir. }\end{array}$ & $\begin{array}{l}\text { Ele acariciava seu velho livro } \\
\text { escolar, que estava em seu } \\
\text { colo, e que ele me ofereceu } \\
\text { mais tarde. }\end{array}$ & Irritação \\
\hline
\end{tabular}

Fonte: Antoinette Errante (2000, p. 161). 
A construção da transcrição, desta forma, permite uma melhor visualização daquilo que foi, afinal, obtido através da entrevista, pois torna possível caracterizar a relação que se estabeleceu entre diálogo, técnicas de ocultação e reações emotivas. Verena Alberti (2008) acrescenta que a parcimônia em determinado trecho de um discurso, assim como mudanças de intensidade na narrativa, tudo isso precisa ser analisado. Outro aspecto a ser destacado são as variações temporais. 0 narrador dialoga animadamente sobre determinado tema que condiz com suas experiências pessoais, entretanto seu humor pode mudar rapidamente quando o eixo segue para outro tema. Isso diz muito acerca de sua perspectiva nos eventos do qual tomou parte, assim como a importância que ele dedica a cada um dos diferentes eventos. Sobre as variações, Verena Alberti (2018, p. 188) analisa algumas pesquisas de História Oral desenvolvidas na Europa no contexto pós Segunda Guerra Mundial, quando a distância da significação entre o que se entende enquanto "fato" e as suas "representações", da perspectiva do sujeito em sua particularidade, é mais marcante: "[...] na França, o 8 de maio de 1945 - o que marca o fim da Segunda Guerra - para muitos não foi tão importante quanto a libertação de Paris na segunda metade do ano anterior."

Assim, torna-se importante assinalar que as variações temporais permitem a adequada compreensão da análise documental. Sejam variações baseadas nas reações emocionais a eventos específicos, como no exemplo da tabela produzida por Antoinette Errante (2000) para o seu diário de campo, ou associadas a deslocamentos temporais trazidos por representações individuais ante ao evento, como demonstram as proposições analisadas por Verena Alberti (2008).

Para assegurar a qualidade da transcrição, alguns cuidados técnicos para sua realização, como a duplicação da gravação, tornam-se necessários para evitar a perda irrecuperável do documento. Também é importante repassar a transcrição com o objetivo de verificar e corrigir possíveis equívocos, além de realizar um copidesque, que consiste em adequar a transcrição às normas da língua escrita, contendo correções gramaticais de regência, concordância, ortografia, acentuação e pontuação. Alguns pontos do copidesque, como a concordância, podem ser opcionais, dependendo dos objetivos das entrevistas, uma vez que a própria linguagem utilizada na narrativa, com seus "erros" e gírias, pode ser um importante fator na análise crítica e social.

Os indicadores relacionados à análise tratam, especificamente, das concepções metodológicas associadas à interpretação crítica do material produzido a partir das entrevistas/narrativas transcritas. A análise/interpretação surge, primeiramente, da consideração do/a entrevistador/a sobre o contexto da narrativa do/a entrevistado/a. É preciso destacar que existe um contexto que abrange o período histórico ao qual a entrevista remete, as características da sociedade, a conjuntura política relacionada à época, assim como a cultura na qual o/a entrevistado/a está inserido/a, tanto no momento da entrevista, quanto também no conteúdo de sua narrativa, portanto. Além disso, é importante analisar em que medida o distanciamento temporal influencia a narrativa. Sobre esse aspecto, especificamente, Antoinette Errante (2000, p. 147) faz uma observação sobre a "lembrança": 
A dimensão complexa do tempo, no que diz respeito às interlocuções entre o presente e o passado e à própria dinâmica de funcionamento da memória, em particular, da "lembrança", conforme é apontado por Antoinette Errante (2000), demonstra que as narrativas comunicam algo e possuem certa intencionalidade, ou seja, as narrativas são profundamente carregadas de subjetividade. Trata-se de uma das características mais significativas das fontes orais, motivo pelo qual recebeu críticas de pesquisadores que, sob determinados paradigmas de ciência, não valorizavam, durante muito tempo, o trabalho realizado a partir dessas fontes. A subjetividade é o trunfo e o desafio do trabalho das fontes orais, embora não seja uma característica exclusiva da fonte oral. Nessa perspectiva, se considerarmos a fonte oral como um documento que efetivamente é, devemos entender que documento na pesquisa é "qualquer fonte sobre o passado, conservado por acidente ou deliberadamente, analisado a partir do presente e estabelecendo diálogos entre a subjetividade atual e a subjetividade pretérita" (KARNAL; TATSCH, 2009, p. 24). Nessa concepção, todo documento resulta e expressa alguma subjetividade, o que potencializa seu caráter de permanente construção.

Vale dizer ainda que as fontes orais são fontes de memória e, por este motivo, consideramos em nosso quadro algumas premissas oriundas do campo da memória social. Desse modo, as narrativas de memória nunca serão apenas aquilo que se lembra, pois memória, além de lembrança, envolve mecanismos coletivos e individuais de silêncio e de esquecimento. Assim, consideramos importante problematizar o fato de que as narrativas de memória também são narrativas de experiência (SILVEIRA; KAHMANN; OLIVEIRA, 2020). Como destacaram Abrahão e Bolívar (2014, p.10), quando falamos em narrativa nos referimos a "una forma de construir realidad, de ordenar la experiencia, apropriarse de ella y de sus significados particulares y colectivos. La narrativa es una modalidad de pensamiento, una forma de organizar la experiencia [...]". Como já tivemos oportunidade de dizer através de outro trabalho de nosso grupo de pesquisa, "consideramos que as narrativas de experiências podem ser compreendidas como formas de significação e atribuição de sentido a realidades vividas, concretas ou imaginadas" (SILVEIRA; KAHMANN; OLIVEIRA, 2020, p.12), isto é, a fonte oral, assim como qualquer outra fonte, não deve ser tratada como um retrato fiel do vivido, mas a resíduos de ação carregados de atribuições de sentido. Ao mesmo tempo, na perspectiva da pesquisa (auto)biográfica (NÓVOA; FINGER, 2014), narrar provoca tanto em quem fala como em quem ouve um "deslocamento de si”, um momento de "autoformação participada", de transformação e de reflexão dos percursos de vida que são comunicados em através da entrevista, o que pode ratificar seu caráter igualmente formativo.

As premissas em relação às entrevistas qualitativas/narrativas, à memória social e coletiva e às narrativas (auto)biográficas guardam relação com esse aspecto que é intrínseco às fontes orais e à abordagem da História Oral. Assim, na base do inventário de ferramentas para os possíveis usos das fontes orais na pesquisa acadêmica, encontra-se o desafio que é imposto a todos/as os/as pesquisadores/as que enveredam pelo campo de estudos da História Oral. A constituição de um inventário cumpre, desta forma, tanto o resultado quanto o percurso até se chegar efetivamente no inventário em si. Esperamos que estas notas possam ser úteis a todos/as que venham a utilizar as fontes orais em suas pesquisas.

\section{CONSIDERAÇõES FINAIS}


A História Oral contribui de um modo bastante original na abordagem de temáticas que consideram a multiplicidade de significados, dando inteligibilidade, especialmente, às experiências individuais e coletivas sobre determinados contextos. No campo de suas metodologias, as entrevistas têm sido frequentemente discutidas pelos/as pesquisadores/as sem deixar de considerar, no entanto, a subjetividade característica das fontes orais. Quando se trata da elaboração de questionários ou de roteiros de entrevista, os/as pesquisadores/as têm refletido justamente sobre essa particularidade da fonte oral. Não que não seja também um atributo de todas as outras fontes históricas, mas as fontes orais tendem a impor desafios ao percurso de pesquisa, sobretudo no que diz respeito aos/às jovens pesquisadores/as.

Ao buscar inventariar premissas teórico-metodológicas das fontes orais enquanto ferramentas para a pesquisa, constituímos, de um modo simplificado - ainda que não simplista - uma síntese sobre como, afinal, lidar com as principais etapas que envolvem o tratamento das fontes orais: sua produção, transcrição e análise. O inventário, formado por categorias e pressupostos, buscou interligar as etapas operacionais do tratamento das fontes orais, sua relação com as entrevistas de cunho qualitativo e algumas das principais dimensões da memória social e coletiva e da pesquisa (auto)biográfica. Todas essas premissas, se encadeadas, permitem, além da constituição do inventário de ferramentas, que se estabeleçam apontamentos acerca da subjetividade presente nas fontes orais. Assim, as reflexões sobre o percurso de constituição do inventário, que acompanharam, ainda que de maneira subjacente, a discussão sobre o tratamento das fontes orais, permitem olhar para o inventário apresentado nesse artigo como um produto do desafio imposto pela pesquisa acadêmica, o que significa dizer que todo/a o/a pesquisador/a, seja iniciante ou não, na trilha de sua investigação, necessitará construir respostas e alternativas aos desafios que a pesquisa lhe impõe.

\section{REFERÊNCIAS}

ABRAHÃO, Maria Helena Menna Barreto; BOLÍVAR, Antonio. Trayectorias epistemológicas y prácticas de la investigación (auto)biográfica en educación em Brasil y España. In: (orgs.). La investigación (auto)biográfica en educación: miradas cruzadas entre Brasil y España. Granada/Porto Alegre: EUG/EdiPUCRS, 2014, p. 8-29.

ALBERTI, Verena. Histórias dentro da História. In: PINSKY, Carla Bassanezi (Org.). Fontes históricas. $3^{\mathrm{a}}$ ed. São Paulo: Contexto, p. 155-202, 2008.

BARROS, José d'Assunção. 0 projeto de pesquisa em História: da escolha do tema ao quadro teórico. 10. ed. Petrópolis, RJ: Vozes, 2015.

CORAZZA, Sandra Mara. Manual infame... mas útil, para escrever uma boa proposta de tese ou dissertação. In: BIANCHETTI, Lucídio; MACHADO NETTO, Ana Maria. A bússula do escrever: desafios e estratégias na orientação e escrita de teses e dissertações. $3^{\mathrm{a}}$ ed. São Paulo: Cortez, 2012.

DINIZ, Célia Regina; SILVA, Iolanda Barbosa da. Metodologia Científica. Campina Grande/Natal: Editora da UEPB/Editora da UFRN, 2008.

ERRANTE, Antoinette. Mas afinal, a memória é de quem? Histórias Orais e Modos de Lembrar e Contar. História da Educação/ASPHE, Pelotas: Ed. da UFPel, n. 8, p. 140-174, 2000.

KARNAL, Leandro; TATSCH, Flavia Galli. A memória evanescente. In: PINSKY, Carla Bassanezi e LUCA, Tânia Regina de (orgs.). O historiador e suas fontes. São Paulo: Contexto, p.9-27 2009. 
MEIHY, José Carlos Sebe Bom. Os Novos Rumos Da História Oral: 0 Caso Brasileiro. Revista de História. 155 $\left(2^{\circ}\right)$, p. 191-203, 2006. Disponível em: <http://www.revistas.usp.br/revhistoria/article/view/19041>. Acesso em: 17 de março de 2020.

MINAYO, Maria Cecília de Souza. Análise qualitativa: teoria, passos e fidedignidade. Ciência \& Saúde Coletiva, 17(3): p. 621-626, 2012. Disponível em: <http://www.scielo.br/scielo.php?script=sci_arttext\&pid=S141381232012000300007>. Acesso em: 15 de março de 2020.

NÓVOA, António; FINGER, Mathias (orgs). 0 método (auto)biográfico e a formação. $2^{\mathrm{a}}$ ed. Natal, RN: EDUFRN, 2014.

PORTELLI, Alessandro. História Oral como Gênero. Projeto História, São Paulo, n. 22, p. 9-36, jun., 2001.

PORTELLI, Alessandro. 0 que faz a história oral diferente. Projeto História, São Paulo, n. 14, p.25-39, fev. 1997.

SILVEIRA, Éder da Silva; KAHMANN, Ana Paula; OLIVEIRA, Amanda Assis de. Entre memória e experiência: algumas reflexões teórico-metodológicas sobre narrativas em fontes autobiográficas. Revista Eletrônica de Educação, v. 14, 1-17, e3245057, jan./dez. 2020. Disponível em:

<http://www.reveduc.ufscar.br/index.php/reveduc/article/view/3245>. Acesso em: 15 de março de 2020.

THOMPSON, Paul. A Voz do Passado. Rio de Janeiro: Paz 